\title{
Effect of Calcium Hydroxide on the Bond Strength of Two Bioactive Cements and SEM Evaluation of Failure Patterns
}

\author{
Carolina Fabiana Centenaro, ${ }^{1}$ Manuela Favarin Santini, ${ }^{1}$ Ricardo Abreu da Rosa, ${ }^{1}$ \\ Angela Longo do Nascimento, ${ }^{1}$ Milton Carlos Kuga, ${ }^{2}$ Jefferson Ricardo Pereira, ${ }^{3}$ and Marcus Vincius Reis Só ${ }^{1}$ \\ ${ }^{1}$ Conservative Dentistry Departament, Federal University of Rio Grande do Sul, Porto Alegre, Rio Grande do Sul, \\ Brazil \\ ${ }^{2}$ Department of Restorative Dentistry, Araraquara Dental School, São Paulo State University, Araraquara, São Paulo, \\ Brazil \\ ${ }^{3}$ Department of Prosthodontics, Dental School, University of Southern Santa Catarina, Tubarão, Santa Catarina, Brazil
}

SUMMARY: The aim of this study was to assess the effect of calcium hydroxide on bond strength of two bioactive cements. One-mm thick longitudinal slabs of root dentin were obtained from freshly extracted human monorradicular teeth $(n=60)$. Simulated root perforations $(1 \mathrm{~mm}$ in diameter) were prepared in radicular dentin. Thereafter, the specimens were randomly divided into two groups $(\mathrm{n}=30)$, according to the repair material: MTA $(\mathrm{n}=30)$ and Biodentine $(\mathrm{BD})$ $(n=30)$. Next, the specimens in each group were further randomly divided into 4 equal subgroups $(\mathrm{n}=15)$ according to the prior use of $\mathrm{Ca}(\mathrm{OH}) 2$ : MTA/Ca $(\mathrm{OH}) 2$ and $\mathrm{BD} / \mathrm{Ca}(\mathrm{OH}) 2$ groups: perforations were filled with calcium hydroxide $[\mathrm{Ca}(\mathrm{OH}) 2]$ and after 7 days, it was removed, and MTA and BD groups: calcium hydroxide dressing were not used. Push-out test was performed at a crosshead speed of $1 \mathrm{~mm} / \mathrm{min}$. Bond strength values were compared statistically using Kruskal-Wallis test and Dunn's post-test at a significance level of 5\%. The failure analysis was performed using a stereoscopic and classified as adhesive, cohesive and mixed. The pushout bond strength of MTA and BD was not affected by the prior use of $\mathrm{Ca}(\mathrm{OH}) 2(\mathrm{p}>0.05)$. BD yielded higher push-out bond strength values compared with those of MTA, regardless of the use of $\mathrm{Ca}(\mathrm{OH}) 2(\mathrm{p}<0.05)$. Mixed failures were predominant in all groups. $\mathrm{Ca}(\mathrm{OH})$ 2 placement for perforations sealing does not alter the

Conflict of interest: None.

Address for reprints: Marcus Vinćius Reis Só, Federal University of Rio Grande do Sul, Faculty of Dentistry, Porto Alegre, Rio Grande do Sul, Brazil, 2492 Ramiro Barcelos street, 90035-003.

E-mail: endo-so@hotmail.com

Received 2 June 2015; revised 4 August 2015; Accepted with revision 21 August 2015

DOI: $10.1002 /$ sca.21266

Published online 1 September 2015 in Wiley Online Library

(wileyonlinelibrary.com). bond strength of MTA and BD to the root dentin. BD presented higher bond strength values than MTA. SCANNING 38:240-244, 2016. (C) 2015 Wiley Periodicals, Inc.

Key words: biodentine, endodontics, dentin, MTA cement, bioactive cements

\section{Introduction}

Root perforation is an accident that may occur during endodontic treatment or post preparation and must triggers an inflammatory process that may lead to loss of tooth insertion. When the perforation is not treated properly, the prognosis of the tooth is doubtful.

Materials used to repair perforations should be well tolerated by peri-radicular tissues and should also provide a proper seal between the periapical tissues and the oral fluids. They should also be easy to handle, dimensionally stable, and radiopaque (Gancedo-Caravia and Garcia-Barbero, 2006; Shokouhinejad et al., 2010).

Mineral trioxide aggregate (MTA) is the most widely used material to seal perforations (Torabinejad and Chivian, '99) because induces regeneration of peri-radicular area, promotes a proper seal between the root canal, and the external surface of the root, sets in the presence of blood, and its biocompatibility (Parirokh and Torabinejad, 2010; Torabinejad and Parirokh, 2010; Vanderweele et al., 2006). Past studies demonstrated that the sealing of furcation perforation with MTA presented great results (Arens and Torabinejad, '96; Tsai et al., 2006), with the rate of radiographic success higher than $82 \%$ (Ghoddusi et al., 2007). However, MTA main disadvantages are the long setting time and the difficulty in handling (Parirokh and Torabinejad, 2010; Torabinejad and Parirokh, 2010). 
Recently, a new calcium silicate-based material, Biodentine (Septodont, Saint-Maur-des-Fossés, France) was specifically designed as a "dentine replacement" material. Biodentine (BD) has a wide range of applications including endodontic repair (root perforations, apexification, resorptive lesions, and retrograde filling material in endodontic surgery), pulp capping, and can be used under resin composite restorations. BD presents good sealing ability, high compressive strengths, short setting time (Han and Okiji, 2011; Koubi et al., 2013), biocompatibility, bioactivity, and biomineralization properties (Laurent et al., 2008; Laurent et al., 2012).

Clinically, the sealing of perforation must be performed immediately in order to minimize bacterial contamination and irritation of the periodontal tissues caused by the use of endodontic irrigants (Meister et al., '79). When the perforation is not treated immediately or in cases of wide perforation, in which profuse bleeding hampers the visualization, a calcium hydroxide $\left[\mathrm{Ca}(\mathrm{OH})_{2}\right]$ dressing can be used previously. This procedure will prevent the growth of granulation tissue into the pulp chamber (Beavers et al., '86) and will reduce the bacterial contamination into the underlying tissues. The use of $\mathrm{Ca}(\mathrm{OH})_{2}$ is also indicated when there is not available time to perform the final treatment with MTA.

When used as root canal dressing, complete removal of $\mathrm{Ca}(\mathrm{OH})_{2}$ from canal walls is not possible, regardless of the technique used (Kuga et al., 2009; Taş demir et al., 2011). It is known that these residues adhered to the root canal walls negatively affect the prognosis of endodontic treatment (Ricucci and Langeland, '97), affecting the adhesion of the filling material to the canal walls (Barbizam et al., 2008) and the cement penetration into dentinal tubules (Çalt and Serper, '99). Besides, after repair of the furcal perforation, the sealing material must withstand the displacement forces generated during condensation of the restorative material. Thus, the aims of this study were to assess the effect of calcium hydroxide on bond strength of two bioactive cements and to evaluate the failure patterns using SEM. The null hypothesis of this study was that there would not have difference statistically significant between the materials used to seal the perforation and there would not have difference statistically significant among the groups using or not calcium hydroxide.

\section{Materials and Methods}

This study was submitted for ethical review and was approved by the Ethical Committee of the Federal University of Rio Grande do Sul (protocol number 20302113.7.0000.5347). The sample size was calculated by using the BioEstat 5.3 software (Instituto de
Desenvolvimento Sustentável Mamirauá, Belém, Brazil) with an $80 \%$ statistical power, a 95\% confidence interval.

Ten monorradicular teeth were used. Only freshly extracted teeth with straight roots were included in this study. One-mm thick longitudinal slabs were prepared using a double-sided diamond disc under water-cooling in a cutting machine (Extec Labcut 1010, Enfield). Standardized simulated perforation sites were created in the radicular dentin using a round bur, and subsequently, F2 rotary nickel-titanium instruments (ProTaper, Dentsply-Maillefer, Baillagues, Switzerland) were used to ensure that all cavities were perpendicular to the slice and with standardized taper of $4 \%$ and diameter of $1.2 \mathrm{~mm}$ at $16 \mathrm{~mm}$ from its tip.

The slabs were positioned over a layer of heavy silicone (Clonage, DFL, Rio de Janeiro, Brazil) in order to enable adequate filling of the perforations, and to avoid displacement of the specimens.

The specimens were randomly divided into two groups according to the repair material: MTA $(\mathrm{n}=30)$ and BD $(\mathrm{n}=30)$. The specimens in each group were further randomly divided into 4 equal subgroups $(\mathrm{n}=15)$ according to the prior use of $\mathrm{Ca}(\mathrm{OH})_{2}: \mathrm{MTA} / \mathrm{Ca}(\mathrm{OH})_{2}$ and $\mathrm{BD} / \mathrm{Ca}(\mathrm{OH})_{2}$ groups: calcium hydroxide paste (Ultracal XS; Ultradent Products Inc, South Jordan, UT) was injected into the canal using a special tip (NaviTip, Ultradent Products Inc.) as recommended by the manufacturer. After 1 week of storage in $100 \%$ humidity at $37^{\circ} \mathrm{C}$, $\mathrm{Ca}(\mathrm{OH})_{2}$ was removed by irrigation using $5 \mathrm{~mL}$ distilled water and MTA and BD groups: no prior intracanal $\mathrm{Ca}(\mathrm{OH})_{2}$ placement before the perforation sealer material.

MTA (Angelus Indústria de Produtos Odontológicos S/ A, Londrina, Brazil) powder was mixed with the manufacturer's supplied liquid until a thick consistency was obtained and was inserted using MTA carrier by a single operator. Biodentine (Septodont, Saint-Maur-desFosses, France) was mixed according to manufacturer's instructions. The freshly mixed BD had a putty-like consistency and was packed in the perforations and inserted as the same manner as MTA. Excess material was removed from the surface of the samples with a scalpel. Subsequently, the samples were wrapped in wet gauze, placed in an incubator at $37^{\circ} \mathrm{C}$ with $100 \%$ humidity for a week.

\section{Push-Out Bond Strength Test}

The specimens were submitted to the push-out test by using an universal testing machine (DL-1000, Emic, Pinhais, SP, Brazil). The compressive load was applied on the apical side of the slab with a metallic device with $0.85 \mathrm{~mm}$ diameter at a crosshead speed of $1 \mathrm{~mm} / \mathrm{min}$. The load necessary to displace the material was recorded. 
The bond strength was calculated using the formula $\mathrm{R}=\mathrm{L} / \mathrm{A}$, where $\mathrm{L}$ is the fracture load $(\mathrm{N})$ and $\mathrm{A}$ is the bonded area $\left(\mathrm{mm}^{2}\right)$. To determine the bonded area (A), the following formula to calculate the lateral area of a circular straight cone with parallel bases was used: $A=2 \pi \times g \times(R 1+R 2)$, where $\pi=3.14, \mathrm{~g}=$ height, $\mathrm{R} 1=$ smaller base's radius, and $\mathrm{R} 2=$ larger base's radius. To determine the inclination $(\mathrm{g})$, the following calculation was used: $\mathrm{g}^{2}=\mathrm{h}^{2}+[\mathrm{R} 2-\mathrm{R} 1]^{2}$, where $\mathrm{h}=$ section height, $\mathrm{R} 1$ and R2 were obtained by measuring the internal diameters of the smaller and larger base using a digital caliper (727, Starrett Indústria e Comércio Ltda, SP, Brazil).

\section{Failure Analysis}

Specimens were prepared for analysis in a scanning electron microscope (JEOL 6060, JEOL; Tokyo, Japan). The specimens were fixed with adhesive tape on a metal device and sputtered with a Pd-Au alloy (MED 010, Balzers Union, Balzers, Liechtenstein, Germany).

All specimens were examined using SEM at $\times 70$ magnification and $10 \mathrm{Kv}$ to determine the failure patterns: adhesive failure between dentin and cement (A); cohesive failure of the cement $(\mathrm{C})$; mixed failure $(\mathrm{M})$.

\section{Statistical Analysis}

The absence of a normal distribution was confirmed by the Shapiro-Wilk test. The data were analyzed statistically by the nonparametric Kruskal-Wallis test and Dunn's post-test at a significance level of 5\% using the BioEstat 5.3 software (Instituto de Desenvolvimento Sustentável Mamirauá, AM, Brazil).

\section{Results}

The push-out bond strength values (MPa) are presented in Table I as median and percentiles P25 and P75. BD yielded higher push-out bond strength values compared with those of MTA, regardless of the use of $\mathrm{Ca}(\mathrm{OH})_{2}(\mathrm{p}<0.05)$. The placement of $\mathrm{Ca}(\mathrm{OH})_{2}$ prior using the bioactive cements had no effect on the bond strength of MTA or BD to root dentin ( $p>0.05)$.

Failure patterns distribution is presented in Table II. In all experimental groups, mixed failure was predominant; therefore the majority of the samples presented mixed failures (63.3\%). Adhesive failures were observed in $35 \%$ of the specimens. Only one cohesive failure of the cement was observed. Figure 1 represents the failure patterns observed using SEM at $\times 40$ magnification.
TABLE I Median 25th (P25) and 75th (P75) percentiles percentiles of bond strength $(\mathrm{MPa})$ between bioactive cements and root dentin

\begin{tabular}{lcccc}
\hline & & $\begin{array}{c}\mathrm{MTA} / \\
\mathrm{Ca}(\mathrm{OH})_{2}\end{array}$ & $\mathrm{BD}$ & $\begin{array}{c}\mathrm{BD} / \\
\mathrm{Ca}(\mathrm{OH})_{2}\end{array}$ \\
\hline $\mathrm{n}$ & 15 & 15 & 15 & 15 \\
Median & $1.53^{\mathrm{A}}$ & $0.79^{\mathrm{A}}$ & $5.70^{\mathrm{B}}$ & $6.50^{\mathrm{B}}$ \\
P25-P75 & $1.10-4.11$ & $0.44-3.24$ & $4.99-9.92$ & $5.94-7.70$
\end{tabular}

\section{Discussion}

The results of this study reject the null hypothesis of this study that there would not have statistically significant differences between the materials used to seal the perforation but confirm the null hypothesis that there would not have statistically significant differences among the groups using or not calcium hydroxide.

The results of present study demonstrated that, regardless to the use of $\mathrm{Ca}(\mathrm{OH})_{2}, \mathrm{BD}$ presented higher bond strength values when compared with MTA $(\mathrm{p}<0.05)$. This result is in agreement with previous studies (Aggarwal et al., 2013; Elnaghy, 2014; Guneser et al., 2013). Biodentine powder is mainly composed of tricalcium silicate, calcium carbonate, and zirconium oxide as the radio-pacifier (Laurent et al., 2008). Both BD and MTA caused the uptake of calcium (Ca) and silicon $(\mathrm{Si})$ in the adjacent root canal dentine in the presence of PBS (Han and Okiji, 2011). Ca and Si uptake most probably causes chemical and structural modification of dentine, which may result in higher acid resistance and physical strength. Although both materials formed tag-like structures, BD may have more prominent biomineralization ability than MTA (Han and Okiji, 2011), which explains the greater values of bond strength presented by BD in the present and in other studies (Elnaghy, 2014; Guneser et al., 2013).

The placement of $\mathrm{Ca}(\mathrm{OH})_{2}$ prior using bioactive materials to seal perforations is used for decontamination of old perforations, to stop bleeding and to avoid granulation tissue growth (Beavers et al., '86). Since calcium hydroxide-based pastes cannot be completely removed from root canals (Kuga et al., 2012; Rödig et al., 2010), some studies evaluated the effect of intracanal calcium hydroxide dressing on the push-out bond strength of endodontic sealers (Amin et al., 2012; Guiotti et al., 2014). Guiotti et al. (2014) observed that $\mathrm{Ca}(\mathrm{OH})_{2}$-based dressings had a negative effect on the push-out bond strength value of the AH Plus sealer, only in the cervical, and apical root thirds. However, in this study, $\mathrm{Ca}(\mathrm{OH})_{2}$ dressings had no effect on bond strength of MTA and BD to the root dentin ( $p>0.05)$.

Although the results did not reveal differences between MTA groups, there is a tendency of reduction on bond strength values presented by MTA when 
TABLE II The failure modes (A: adhesive, C: cohesive, M: mixed) distribution in the experimental groups

\begin{tabular}{|c|c|c|c|c|c|}
\hline Failures patterns & MTA & MTA / Ca $(\mathrm{OH})_{2}$ & $\mathrm{BD}$ & $\mathrm{BD} / \mathrm{Ca}(\mathrm{OH})_{2}$ & Overall \\
\hline Adhesive & $4(26.7 \%)$ & $5(33.3 \%)$ & $7(46.7 \%)$ & $5(33.3 \%)$ & $21(35 \%)$ \\
\hline Cohesive & $0(0 \%)$ & $1(6.7 \%)$ & $0(0 \%)$ & $0(0 \%)$ & $1(1.7 \%)$ \\
\hline Mixed & $11(73.3 \%)$ & $9(60 \%)$ & $8(53.3 \%)$ & $10(66.7 \%)$ & $38(63.3 \%)$ \\
\hline Overall & $15(100 \%)$ & $15(100 \%)$ & $15(100 \%)$ & $15(100 \%)$ & $60(100 \%)$ \\
\hline
\end{tabular}

$\mathrm{Ca}(\mathrm{OH})_{2}$ dressing was used. Correlating the effect of $\mathrm{Ca}(\mathrm{OH})_{2}$ on the mechanical behavior of MTA in an in vivo experimental design, Felippe et al. (2005) observed that previous use of $\mathrm{Ca}(\mathrm{OH})_{2}$ paste was strongly related to the extrusion of MTA and formation of mineralized barriers beyond the limits of the root canal walls. The authors attributed their findings to the necrosis and dissolution of periapical tissue presented by calcium hydroxide paste in the foramen area. Initially, the latter study is an in vivo experiment that aimed to assess the apical seal of teeth with incomplete root formation. In that case, MTA was placed into the canals with a lentulo-spiral and immediately condensed in the apical third by gentle packing with paper points. In the current study, MTA and BD were condensed over a heavy silicon layer to simulate the resistance of condensation promoted by periodontal structures. Finally, the bond strength test was only performed after complete material set. It is recommended that the plunger size be set just slightly smaller than the perforation diameter (Nagas et al., 2011; Chen et al., 2013). Therefore, care was taken to use a plunger with a size $(0.85 \mathrm{~mm}$ in diameter) that was set closer to the diameter of the perforation $(1.2 \mathrm{~mm}$ in diameter) and then to promote stress concentration near to the cement/dentin interface.
The bond strength values obtained in this study are lower than those presented in the literature (Aggarwal et al., 2013; Elnaghy, 2014; Guneser et al., 2013). This can be justified because, in previous studies, the data were presented as mean and standard deviation. Shapiro-Wilk test revealed a non-normal distribution of the data, thus non-parametric analysis was performed. At statistical standpoint, when a non-normal distribution is achieved, the better way to represent the data is using median and 25th and 75th percentiles.

Mixed failure patterns were predominant in all groups, irrespective of the $\mathrm{Ca}(\mathrm{OH})_{2}$ placement and the bioactive material used to seal the root perforations. Previous studies (Aggarwal et al., 2013; Elnaghy, 2014; Guneser et al., 2013) reported the predominance of adhesive failures associated with MTA and cohesive ones associated with BD. The controversial results of the present study may be attributed to the different methodology used for specimen preparation. In this study the perforations presented tapered lateral walls, while in previous studies these walls were parallels to each other (Aggarwal et al., 2013; Guneser et al., 2013; Elnaghy, 2014). Parallel walls preparation induces higher bond strength values due to the micromechanical retention between cement and dentin. Moreover,
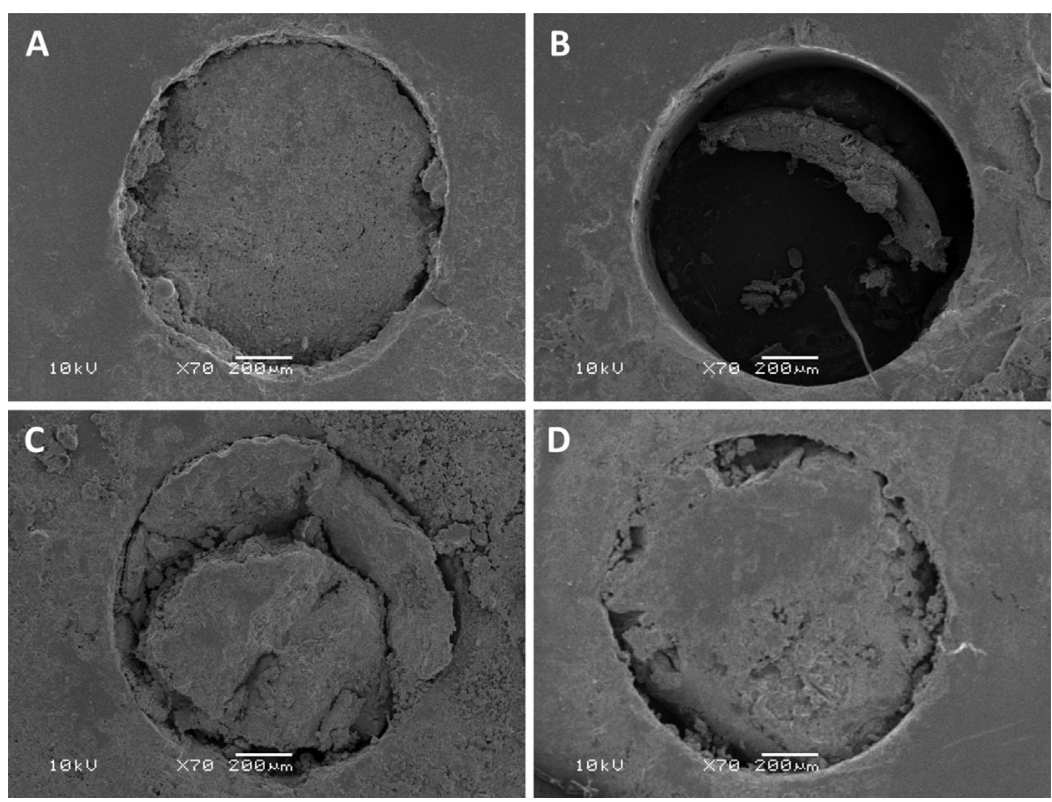

Fig 1. Scanning electron microscopy photomicrographs of bioactive cements/dentin interfaces. A: Mixed failure of MTA. B: Adhesive failure of BD. C: Cohesive failure of MTA/Ca(OH $)_{2}$; and D: Mixed failure BD/Ca(OH $)_{2}$. 
parallel preparation generates greater number of cohesive failures in comparison with tapered ones.

\section{Conclusions}

Based on this in vitro study, it is possible to conclude that the force needed for the displacement of BD from artificial root perforations was significantly higher than MTA. $\mathrm{Ca}(\mathrm{OH})_{2}$ placement prior to the perforations' sealing does not alter the bond strength of MTA and BD to root dentin. Mixed failures were predominant in all experimental groups.

\section{References}

Aggarwal V, Singla M, Miglani S, Kohli S. 2013. Comparative evaluation of push-out bond strength of ProRoot MTA, Biodentine, and MTA Plus in furcation perforation repair. J Conserv Dent 16:462-465.

Arens DE, Torabinejad M. 1996. Repair of furcal perforations with mineral trioxide aggregate: two case reports. Oral Surg Oral Med Oral Pathol Oral Radiol Endod 82:84-88.

Barbizam JV, Trope M, Teixeira EC, Tanomaru-Filho M, Teixeira FB. 2008. Effect of calcium hydroxide intracanal dressing on the bond strength of a resin-based endodontic sealer. Braz Dent J 19:224-227.

Beavers RA, Bergenholtz G, Cox CF. 1986. Periodontal wound healing following intentional root perforations in permanent teeth of Macaca mulatta. Int Endod J 19:36-44.

Çalt S, Serper A. 1999. Dentinal tubule penetration of root canal sealers after root canal dressing with calcium hydroxide. J Endod 25:431-433.

Chen WP, Chen YY, Huang SH, Lin CP. 2013. Limitations of pushout test in bond strength measurement. J Endod 39:283-287.

Elnaghy AM. 2014. Influence of QMix irrigant on the micropushout bond strength of biodentine and white mineral trioxide aggregate. J Adhes Dent 16:277-283.

Felippe WT, Felippe MC, Rocha MJ. 2005. The effect of mineral trioxide aggregate on the apexification and periapical healing of teeth with incomplete root formation. Int Endod J 39:2-9.

Gancedo-Caravia L, Garcia-Barbero E. 2006. Influence of humidity and setting time on the push-out strength of mineral trioxide aggregate obturations. J Endod 32:894-896.

Ghoddusi J, Sanaan A, Shahrami F. 2007. Clinical and radiographic evaluation of root perforation repair using MTA. N Y State Dent J 73:46-49.

Guiotti FA, Kuga MC, Duarte MA, Sant'Anna AJ, Faria G. 2014. Effect of calcium hydroxide dressing on push-out bond strength of endodontic sealers to root canal dentin. Braz Oral Res 28:1-6.
Guneser MB, Akbulut MB, Eldeniz AU. 2013. Effect of various endodontic irrigants on the push-out bond strength of biodentine and conventional root perforation repair materials. J Endod 39:380-384.

Han L, Okiji T. 2011. Uptake of calcium and silicon released from calcium silicate-based endodontic materials into root canal dentine. Int Endod J 44:1081-1087.

Koubi G, Colon P, Franquin JC, et al. 2013. Clinical evaluation of the performance and safety of a new dentine substitute, Biodentine, in the restoration of posterior teeth-a prospective study. Clin Oral Investig 17:243-249.

Kuga MC, Campos EA, Faria-Junior NB, Só MV, Shinohara AL. 2012. Efficacy of NiTi rotary instruments in removing calcium hydroxide dressing residues from root canal walls. Braz Oral Res 26:19-13.

Laurent P, Camps J, About I. 2012. Biodentine ${ }^{\mathrm{TM}}$ induces TGF$\beta 1$ release from human pulp cells and early dental pulp mineralization. Int Endod J 45:439-448.

Laurent P, Camps J, De Méo M, Déjou J, About I. 2008. Induction of specific cell responses to a $\mathrm{Ca}(3) \mathrm{SiO}(5)$-based posterior restorative material. Dent Mater 24:1486-1494.

Meister F, Jr, Lommel TJ, Gerstein H, Davies EE. 1979. Endodontic perforations which resulted in alveolar bone loss. Oral Surg Oral Med Oral Pathol 47:463-470.

Nagas E, Uyanik O, Durmaz V, Cehreli ZC. 2011. Effect of plunger diameter on the push-out bond values of different root filling materials. Int Endod J 44:950-955.

Parirokh M, Torabinejad M. 2010. Mineral trioxide aggregate: a comprehensive literature review-part I: chemical, physical, and antibacterial properties. J Endod 36:16-27.

Ricucci D, Langeland K. 1997. Incomplete calcium hydroxide removal from the root canal: a case report. Int Endod $\mathbf{J}$ 30:418-421.

Rödig T, Vögel S, Zapf A, Hülsmann M. 2010. Efficacy of different irrigants in the removal of calcium hydroxide from root canals. Int Endod J 43:519-527.

Shokouhinejad N, Nekoofar MH, Iravani A, Kharrazifard MJ, Dummer PM. 2010. Effect of acidic environment on the pushout bond strength of mineral trioxide aggregate. J Endod 36:871-874.

Taşdemir T, Celik D, Er K, et al. 2011. Efficacy of several techniques for the removal of calcium hydroxide medicament from root canals. Int Endod J 44:505-509.

Torabinejad M, Chivian N. 1999. Clinical applications of mineral trioxide aggregate. J Endod 25:197-105.

Torabinejad M, Parirokh M. 2010. Mineral trioxide aggregate: a comprehensive literature review-part II: leakage and biocompatibility investigations. J Endod 36:190-102.

Tsai YL, Lan WH, Jeng JH. 2006. Treatment of pulp floor and stripping perforation by mineral trioxide aggregate. J Formos Med Assoc 105:522-526.

Vanderweele RA, Schwartz SA, Beeson TJ. 2006. Effect of blood contamination on retention characteristics of MTA when mixed with different liquids. J Endod 32: 421-424. 